\title{
Severity of COVID-19: The importance of being hypertensive
}

\author{
Fabio Angeli ${ }^{1,2}$, Sergio Masnaghetti ${ }^{1,2}$, Dina Visca ${ }^{1,2}$, Alessandra Rossoni ${ }^{1,2}$, Sara Taddeo ${ }^{1,2}$, \\ Filippo Biagini ${ }^{1,2}$, Paolo Verdecchia ${ }^{3}$
}

${ }^{1}$ Department of Medicine and Surgery, University of Insubria, Varese; ${ }^{2}$ Department of Medicine and Cardiopulmonary Rehabilitation, Maugeri Care and Research Institute, IRCCS Tradate, Varese; ${ }^{3}$ Fondazione Umbra Cuore e Ipertensione ONLUS and Division of Cardiology, Hospital S. Maria della Misericordia, Perugia, Italy

The novel respiratory Syndrome Coronavirus-2 (SARS-CoV-2) caused a cluster of pneumonia cases in China at the end of 2019. After few months, it led to a pandemic that has spread throughout most countries of the world (https://coronavirus.jhu.edu/map.html).

SARS-CoV-2 disease (COVID-19) primarily manifests as a lung infection and its clinical course is characterized by respiratory symptoms ranging from a mild respiratory infection (including fever, cough and fatigue) to pneumonia, acute respiratory distress syndrome (ARDS), shock, and death [1]. Among the proposed mechanisms of injury caused by SARS-CoV-2, there is a "cytokine storm" triggered by an imbalanced response by type 1 and type $2 \mathrm{~T}$ helper cells [2]. Furthermore, an emerging body of evidence suggests that COVID-19 may predispose patients to arterial and venous thrombotic disease [3]. Fibrin deposits are found in the lungs possibly due to the dysregulation of the coagulation and fibrinolytic systems: tissue factor is exposed on damaged alveolar endothelial cells promoting fibrin deposition, while significantly elevated levels of plasminogen activator inhibitor 1

Correspondence: Prof. Fabio Angeli, Department of Medicine and Surgery, University of Insubria, Varese and Department of Medicine and Cardiopulmonary Rehabilitation, ICS Maugeri IRCCS, Institute of Tradate, Via Crotto Roncaccio 16, Tradate (VA), Italy.

Tel. +39.0331.829630 - Fax: +39.0331.829400.

E-mail: angeli.internet@gmail.com

Contributions: All authors have contributed equally to the manuscript. All authors gave final approval and agree to be accountable for all aspects of work ensuring integrity and accuracy.

Conflict of interest: the authors declare no conflict of interest.

Key words: COVID-19; SARS-CoV-2; hypertension; prognosis; angiotensin; $\mathrm{ACE}_{2}$

Received for publication: 11 May 2020.

Accepted for publication: 13 May 2020.

${ }^{\circ}$ Copyright: the Author(s), 2020

Licensee PAGEPress, Italy

Monaldi Archives for Chest Disease 2020; 90:1372

doi: 10.4081/monaldi.2020.1372

This article is distributed under the terms of the Creative Commons Attribution Noncommercial License (by-nc 4.0) which permits any noncommercial use, distribution, and reproduction in any medium, provided the original author(s) and source are credited.
(PAI-1) from lung epithelium and endothelial cells create a hypofibrinolytic state [3].

Numerous clinical studies showed that COVID-19 disproportionately affects patients with pre-existing comorbidities. According to a meta-analysis of 7 studies including 1576 laboratory-confirmed COVID-19 infected patients, the most prevalent comorbidity was hypertension [4]. Furthermore, patients with hypertension appear to be at increased risk from COVID-19 infection. More specifically, a pooled analysis of 13 studies, with a total of 2893 patients with COVID-19 documented that hypertension was associated with a 2.5-fold increased risk of severe COVID-19 (odds ratio [OR]: 2.49; $95 \%$ confidence interval $[\mathrm{CI}]: 1.98-3.12 ; \mathrm{I}^{2}=24 \%$ ) and a higher risk of mortality (OR: $2.42 ; 95 \%$ CI: 1.51-3.90; $\mathrm{I}^{2}=0 \%$ ) [5].

Taken together, these findings suggest that hypertension is linked to the pathogenesis of COVID-19. In this regard, the reninangiotensin-aldosterone-system (RAAS) plays an important role in the pathogenesis of hypertension and the pathways involved in the generation of angiotensin II (Ang II) and Angiotensin ${ }_{1,7}\left(\mathrm{Ang}_{1,7}\right)$ have been recently recognized as potential markers of COVID-19 severity. Angiotensin converting enzyme-2 $\left(\mathrm{ACE}_{2}\right)$ receptors are involved in the degradation of Ang II to $\mathrm{Ang}_{1,7}$, but they also mediate the entry into the cell of SARS-CoV-2. Of note, $\mathrm{Ang}_{1,7}$ opposes the deleterious effects of Ang II, including vasoconstriction, proliferative, profibrofitic and proinflammatory effects, and prothrombotic actions. The entry of SARS-CoV2 into the cells through membrane fusion markedly down-regulates $\mathrm{ACE}_{2}$ receptors, with loss of the catalytic effect of these receptors at the external site of the membrane. Thus, this phenomenon translates in an increased state of pulmonary inflammation and coagulation (Figure 1).

It has been noted that hypertension may be associated with a variable degree of $\mathrm{ACE}_{2}$ deficiency [6,7]. In this setting, $\mathrm{ACE}_{2}$ down-regulation induced by SARS-CoV2 has the potential to be detrimental in hypertensive patients through a further worsening

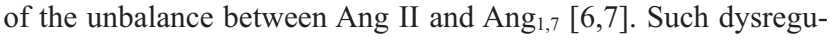
lation would markedly decrease the activity of $\mathrm{Ang}_{1,7}$, thereby rendering the lungs more susceptible to the detrimental actions of Ang II (Figure 1). In other words, the progression of inflammatory and thrombotic processes may be triggered by Ang II hyperactivity unopposed by $\mathrm{Ang}_{1,7}[6]$.

Paraphrasing an aphorism of Oscar Wilde (from "The importance of being Earnest", 1895), we could state that "the truth is rarely pure and never simple". This appears particularly true for the complex mechanisms linking COVID-19 with hypertension. The theorized physiopathological unbalance between Ang II and $\mathrm{Ang}_{1,7}$ might play a central role in explaining many clinical features of COVID-19. Notably, it also provides a solid rationale to investigate the impact of some therapeutic measures which include the use of Ang II type 1 receptor blockers, soluble recombinant $\mathrm{ACE}_{2}$ and $\mathrm{Ang}_{1,7}[6,7]$. 


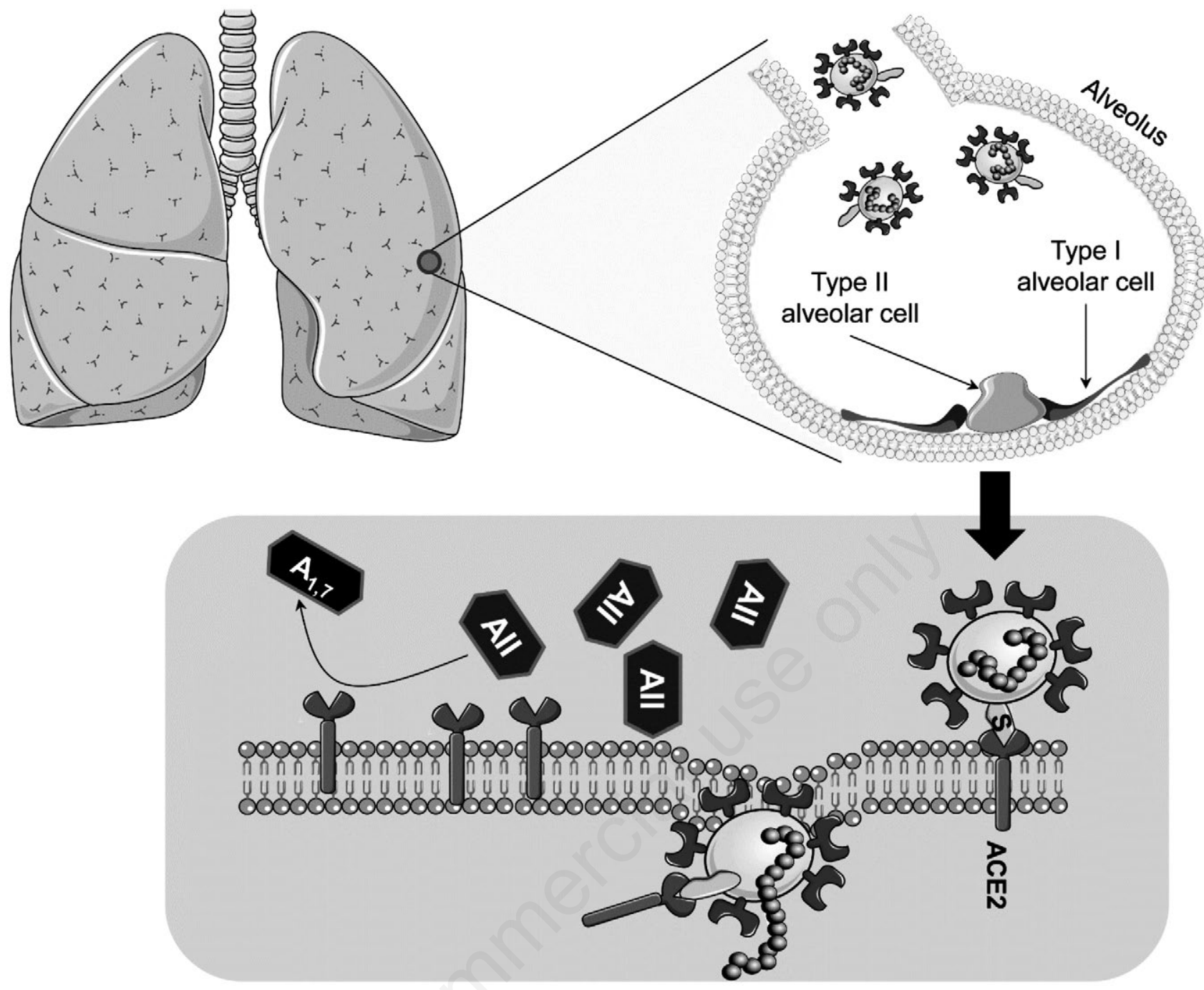

Figure 1. Lung damage during COVID-19. Detrimental effects of $\mathrm{ACE}_{2}$ down-regulation induced by viral entry in a setting of pre-existing $\mathrm{ACE}_{2}$ deficiency (see text for details). $\mathrm{ACE}_{2}$ are mainly expressed in pneumocytes type II, which are responsible for the production of alveolar surfactant, and have the function of 'stem' cells, progenitors of pneumocytes type I (responsible of gas exchanges). AII, angiotensin II; $\mathrm{A}_{1,7}$, angiotensin 1,$7 ; \mathrm{ACE}_{2}$, angiotensin converting enzyme- 2 .

\section{References}

1. Verdecchia P, Reboldi G, Cavallini C, et al. [ACE-inhibitors, angiotensin receptor blockers and severe acute respiratory syndrome caused by coronavirus].[Article in Italina] G Ital Cardiol 2020;21:321-7.

2. Zheng YY, Ma YT, Zhang JY, Xie X. COVID-19 and the cardiovascular system. Nat Rev Cardiol 2020;17:259-60.

3. Whyte CS, Morrow GB, Mitchell JL, et al. Fibrinolytic abnormalities in acute respiratory distress syndrome (ARDS) and versatility of thrombolytic drugs to treat COVID-19. J Thromb Haemost 2020
4. Yang J, Zheng Y, Gou X, et al. Prevalence of comorbidities and its effects in coronavirus disease 2019 patients: A systematic review and meta-analysis. Int J Infect Dis 2020;9 4:91-5.

5. Lippi G, Wong J, Henry BM. Hypertension in patients with coronavirus disease 2019 (COVID-19): a pooled analysis. Pol Arch Intern Med 2020;130:304-9.

6. Verdecchia P, Angeli F, Reboldi G. Angiotensin-converting enzyme inhibitors, angiotensin II receptor blockers and coronavirus. J Hypertens 2020;38:1190-1.

7. Verdecchia P, Cavallini C, Spanevello A, Angeli F. The pivotal link between ACE2 deficiency and SARS-CoV-2 infection. Eur J Intern Med 2020. 